\title{
Psicolinguística
}

\section{experimental: interfaces e multidisciplinaridade}

\author{
Bianca Chaves Leite LIGNANI (D) \\ Universidade Federal de Juiz De Fora (UFJF)
}

\section{RESUMO}

A mesa Psicolinguística Experimental em Interfaces, proposta pela Abralin, tem como escopo os avanços de três áreas importantes que estão em interface com a Psicolinguística Experimental: as Neurociências, o processamento multimodal e a Aquisição da Linguagem (AL). A Prof. ${ }^{a}$ Dra. Lilian Hübner (PUCRS) apresenta experimentos que focalizam a compreensão e a produção da língua em participantes com diferentes níveis socioeconômicos e de escolaridade. São discutidas também pesquisas em pacientes com Doença de Alzheimer, Comprometimento Cognitivo Leve (CCL), ou quadro de problemas linguísticos pós-AVC. A segunda interface, discutida pela Prof. ${ }^{a}$ Dra. Erica Rodrigues (PUCRJ), aborda a multimodalidade do processamento linguístico, defendendo que os aspectos não linguísticos (como imagens e gráficos) devem ser considerados para a compreensão do processamento linguístico como um todo. Finalmente, a Prof. a Dra. Cristina

EDITADO POR Raquel Freitag

AVALIADO POR Lilian Hübner Name enfatiza a atuação da psicolinguística experimental na área da Aquisição da Linguagem, com foco na prosódia da Fala Dirigida à Criança (FDC).

\section{ABSTRACT}

The round-table Psicolinguística Experimental em Interfaces (Experimental Psycholinguistics in Interfaces) proposed by Abralin aims to present the advances in three very productive and important areas that are in interfaced with Experimental Psycholinguistics: Neurosciences, multimodal processing and Language Acquisition (LA). Prof. Dr. Lilian Hübner (PUCRS) presents experiments that focus on the comprehension and production of language in participants with different socioeconomic and educational levels. There are also discussions about research on patients with Alzheimer's disease, Mild 


\section{REVISTA DA ABRALIN}

Cognitive Impairment (MCI) and the post-stroke language impairment. The second interface, discussed by Prof. Dr. Erica Rodrigues (PUCRJ), approaches the multimodality of linguistic processing, arguing that non-linguistic aspects (such as images and graphics) should be considered to understand completely linguistic processing. Finally, Prof. Dr. Cristina Name emphasizes the performance of experimental psycholinguistics in the area of Language Acquisition, with emphasis in prosody in Infant-Directed Speech (IDS).

PALAVRAS-CHAVE

Psicolinguística. Experimental. Interfaces.

\section{KEYWORDS}

Psycholinguistics. Experimental. Interfaces.

Psicolinguística é a área das Ciências Cognitivas que busca esclarecer como se dão a produção, a compreensão e o armazenamento da língua, através das representações mentais ${ }^{1} \mathrm{e}$ do processamento da língua. (WARREN, 2013). Esse rico campo acadêmico considera como objetos de estudo todos os processos cognitivos linguísticos e qualquer estrutura anatômica ou fenômeno fisiológico que possa interferir ou facilitar a compreensão de como os humanos interagem com a linguagem.

Por estar relacionado a uma gama tão ampla de conhecimentos, parece inevitável que a Psicolinguística seja tangente a outras áreas da ciência, sobretudo às áreas da Saúde - principalmente, dentro nas Neurociências. Essa interseção possibilita o desenvolvimento de métodos, ferramentas e hipóteses para os estudos psicolinguísticos, e os frutos dessas investigações são benéficos para todas as disciplinas da ciência.

Lilian Hübner, em sua palestra, inicialmente apresenta dados empíricos sobre como a escolaridade, o nível socioeconômico e os hábitos de leitura e escrita estão intimamente relacionados ao desenvolvimento ou não de demência. É importante ressaltar que os aspectos socioeconômicos são considerados nessa avaliação porque, em geral, estão atrelados à escolaridade. (SOUSA; HÜBNER, 2017).

As diferentes interações sensoriais com a língua (fala, audição, escrita e leitura) parecem ter um papel de proteção cerebral, prevenindo ou adiando os estágios demenciais (STERN, 2012). Dessa forma, pessoas com poucos hábitos de leitura ou com pouca ou nenhuma escolaridade tendem a ter mais chances de desenvolver demência. (ARDILA et al., 2000; ARDILA et al., 2010).

1 Não se deve associar o "mentalismo" a um fenômeno obscuro e oculto ou mesmo intangível. A leitura de Sternberg (2010) esclarece que o termo "mental" é empregado para se referir e sintetizar todos os diversos fenômenos cognitivos que não podem ser percebidos, mas acontecem simultaneamente no interior de cada indivíduo através do acionamento de estruturas anatomofiosiológicas. 


\section{REVISTA DA ABRALIN}

Um conceito importante nos estudos que consideram o funcionamento das capacidades cognitivas é o de fluência verbal ${ }^{2}$ (FV). Em sua apresentação, Lilian Hübner confirma como tarefas de FV podem ser úteis para aferir processamento linguístico atípico, o que pode auxiliar muito no diagnóstico de comprometimento cognitivo em diferentes níveis.

Além disso, fica demonstrado que hábitos de leitura e escrita têm implicatura maior na fluência fonêmica em comparação com a categórica e a livre. Talvez isso esteja relacionado ao fato de que a codificação de estímulos em memória de curto prazo tem natureza acústica; portanto, é mais comum que haja confusão entre sons diante do erro em recuperar palavras. Por outro lado, a memória de longo prazo é codificada principalmente de maneira semântica, ou seja, a partir do significado das palavras (STERNBERG, 2010).

Ainda, é importante considerar que a literacia, fortalecida por maiores hábitos de leitura e de escrita, parece dar suporte para a evocação de palavras na FV baseada na letra ou no fonema inicial.

Esses dados são congruentes com a ordem dos sintomas da demência: a memória de curto prazo é afetada antes da memória de longo prazo (ABREU; FORLENZA; BARROS, 2005). Logo, se as informações acústicas são mais íntimas ao tipo de memória inicialmente afetada pela demência, serão também primariamente prejudicadas.

Lilian Hübner apresenta a psicolinguística experimental não só como área de aplicação das ciências da Saúde, mas também como contribuinte na construção de conhecimentos anatomofisiológicos. A importância da multidisciplinaridade fica evidente ao serem destacadas pesquisas em psicolinguística que permitem um aprofundamento sobre as funções das estruturas da anatomia humana.

Em suma, estudos psicolinguísticos em interface com as neurociências apresentam importantes dados e validações para as áreas de Linguística e Saúde, no geral, uma vez que ajudam na compreensão dos processos cognitivos e dos efeitos que estes têm sobre os indivíduos.

Na palestra de Erica Rodrigues, é introduzida uma proposta multimodal de abordagem psicolinguística na tarefa de leitura, em que os estímulos não linguísticos têm tanta importância para o processamento de informações quanto o parsing ${ }^{3}$. A pesquisadora defende que o texto, embora contenha predominantemente elementos verbais, é composto também por um grupo de estímulos visuais que contribuem ativamente para a construção do sentido e, consequentemente, para a interpretação pelo leitor.

A multimodalidade tem ganhado certa expressividade nas últimas décadas e se trata de um modelo que considera diferentes modos de estímulos contribuindo para o processamento da informação. No caso de um texto escrito, por exemplo, imagens, gráficos ou configuração e formato de organização dos estímulos verbais têm implicação na forma como o leitor interpreta as informações.

2 Atividade de função executiva e avaliativa da linguagem.

3 Processamento sintático dos enunciados, que considera sequências de palavras agrupadas e organizadas em uma estrutura hierárquica (TRAXLER, 2012). 


\section{REVISTA DA ABRALIN}

Entretanto, Erica Rodrigues ressalta o fato de que quase todos os trabalhos acadêmicos que discutem multimodalidade são em Linguística Aplicada, como os de Queiroz (2005) e Duarte (2008), havendo apenas o recente trabalho de Fragoso (2015) para contribuir na área da psicolinguística.

De fato, a psicolinguística experimental aparenta ter meios para entregar grandes contribuições no âmbito do processamento de informações multimodais, posto que considera, para seus estudos, a percepção sensorial e detém instrumentos capazes de avaliar a interação entre os estímulos e quem os recebe.

Empiricamente, a exposição de Erica Rodrigues elucida trabalhos muito relevantes, que usam a técnica de rastreamento ocular ${ }^{4}$ para investigar a compreensão multimodal, com foco na leitura de gráficos e no letramento estatístico, observando o processamento das informações linguísticas e não linguísticas contidas na compreensão e na leitura de gráficos.

A conclusão à que se chega é favorável à adoção da multimodalidade: os estímulos não verbais não só são considerados, mas também têm a capacidade de tornar o processamento das informações linguísticas menos ou mais custoso para o leitor. (FRAGOSO, 2015).

Cristina Name, em sua apresentação, discute as características da Fala Dirigida à Criança (FDC) e, posteriormente, o seu papel na Aquisição da Linguagem (AL). Em comparação com a Fala Dirigida a Adultos e crianças mais velhas, a FDC é marcada por frases mais curtas, com menor grau de complexidade. Além disso, um elevado número de interrogativas compõe esse tipo de fala, o que é curioso, porque é sabido que crianças muito jovens não terão postura de resposta efetiva diante das provocações.

As pesquisas mais recentes sobre FDC desenvolvidas por Cristina Name usam como metodologia a avaliação de questões fonéticas e prosódicas específicas desse tipo de fala no software Praat ${ }^{5}$.

Avaliou-se anteriormente que, no Português Brasileiro, a grande predominância em interrogativas é de contornos prosódicos ascendentes (MORAES, 2008), o que converge com outra característica da FDC: o pitch ${ }^{6}$ mais alto. Além disso, a FDC também apresenta evidências de ampla extensão de pitch, o que também se assemelha ao contorno das interrogativas em Português Brasileiro.

Contudo, considerando apenas as sentenças interrogativas, a maioria delas é composta por perguntas QU-, que apresentam majoritariamente contorno prosódico descendente. Isso faz pensar que, se as perguntas não são dirigidas na expectativa de uma resposta verbal, a intenção dos adultos - e crianças mais velhas - talvez seja mesmo simplesmente interagir com a criança.

\footnotetext{
$4 \mathrm{O}$ rastreamento ocular permite que sejam registrados os movimentos dos olhos de um indivíduo. Nas pesquisas psicolinguísticas, isso é importante para que se compreenda a maneira como as informações são percebidas e organizadas. (KLEIN; BULLA, 2010).

5 "Praat é um programa para analisar, sintetizar e manipular a fala e outros sons, e para criar gráficos em qualidade de publicação" (BOERSMA; WEENICK, 2020).

6 O pitch se refere à sensação melódica: como são percebidos agudos e graves (LADD, 2019). O pitch mais alto dá a sensação de "fala exagerada".
} 


\section{REVISTA DA ABRALIN}

Normalmente, a resposta de uma pergunta QU- exige muito mais estímulos fonéticos, fonológicos, visuais e semânticos do que uma pergunta $\mathrm{S} / \mathrm{N}$. Afinal, respostas do tipo $\mathrm{S} / \mathrm{N}$ são binárias e, normalmente, curtas, enquanto que respostas do tipo QU- podem articular muito mais significados e significantes.

Não obstante, a FDC acentua certas características melódicas, o que tem sido especulado, no âmbito da Aquisição da Linguagem, como importante para a capacidade inicial da criança de distinguir diferentes tipos de sentenças entre si (declarativas vs. interrogativas; perguntas QU- vs. perguntas $\mathrm{S} / \mathrm{N})$.

Apesar de não ser universalmente utilizada, a FDC aparenta ser mais eficiente na interação com bebês, desde recém-nascidos até os quinze meses de idade. Isso porque eles preferem e respondem melhor a estímulos com características desse tipo de fala, como comprovam os trabalhos de Cooper e Aslin $(1990 ; 1994)$.

A palestra de Cristina Name ilustra quanto e como os estudos na área da prosódia podem contribuir para a Psicolinguística Experimental (e vice-versa).

\section{REFERÊNCIAS}

ABREU, I. D.; FORLENZA, O. V.; BARROS, H. L. de. Demência de Alzheimer: correlação entre memória e autonomia. Archives of Clinical Psychiatry, São Paulo, v. 32, n. 3, p. 131-136, 2005.

ARDILA, A. et al. Illiteracy: the neuropsychology of cognition without reading. Archives of clinical neuropsychology, v. 25, n. 8, p. 689-712, 2010 .

ARDILA, A. et al. Age-related cognitive decline during normal aging: the complex effect of education. Archives of clinical neuropsychology, v. 15, n. 6, p. 495-513, 2000.

BOERSMA, P.; WEENICK, D. Praat: doing phonetics by computer. Version 6.1. 15[S. 1.], 20 maio 2020. Disponível em: < https://www.fon.hum.uva.nl/praat/>. Acesso em: 06 jun 2020.

COOPER, R. P.; ASLIN, R. N. Preference for infant-directed speech in the first month after birth. Child development, v. 61, n. 5, p. 1584-1595, 1990.

COOPER, R. P.; ASLIN, R. N. Developmental differences in infant attention to the spectral properties of infant-directed speech. Child development, v. 65, n. 6, p. 1663-1677, 1994. DOI: https://doi.org/10.1111/j.1467-8624.1994.tb00841.x

DUARTE, V. M. Textos multimodais e letramento: habilidades na leitura de gráficos da Folha de São Paulo por um grupo de alunos do ensino médio. 235f. Dissertação (Mestrado em Estudos Linguísticos) - Faculdade de Letras, Universidade Federal de Minas Gerais, Belo Horizonte, 2008. Disponível em: https://repositorio.ufmg.br/bitstream/1843/ARCO-7FVRTQ/1/viviane_mduarte_diss.pdf. Acesso em: 07 jul 2020.

FRAGOSO, L. C. P. Integração de informação linguística e a gráfica na compreensão multimodal de gráficos - uma avaliação psicolinguística. 219f. Tese (Doutorado em Estudos da Linguagem) - Faculdade de Letras, PUC-RIO, Rio de Janeiro, 2015. Disponível em: https://www.maxwell.vrac.puc-rio.br/25595/25595.PDF. Acesso em: 07 jul 2020.

KLEIN, A. I.; BULLA, J. P. Eye-Tracking e linguística: aplicações e interfaces. Letrônica, v. 3, n. 2, p. 235-249, 2010. 


\section{REVISTA DA ABRALIN}

LADD, D. R. O que é prosódia?. Working Papers em Linguística, v. 20, n. 1, p. 8-46, 2019.

MORAES, J. A. The pitch accents in Brazilian Portuguese: analysis by synthesis. In: Speech Prosody. Campinas. Proceedings of the Speech Prosody 2008 Conference. Campinas: Laboratório de Fonética Acústica - Faculdade de Letras UFRJ/CNPq, 2008, p. 389397.

PSICOLINGUÍSTICA experimental em interfaces. Conferência apresentada por Lilian Hübner, Érica Rodrigues e Cristina Name [s.l., s.n], 2020. 1 vídeo (2h 34min 50s). Publicado pelo canal da Associação Brasileira de Linguística. Disponível em: https://www.youtube.com/watch?v=-7wLKZllyPE\&t=7445s Acesso em: 07 jul 2020.

QUEIROZ, A. K. Gêneros Visuais Multimodais em Livros didáticos: usos e tipos. 149f. Dissertação (Mestrado em Letras) - Faculdade de Letras, Universidade Federal de Pernambuco, Recife, 2005. Disponível em: https://repositorio.ufpe.br/bitstream/123456789/7982/1/arquivo8418_1.pdf. Acesso em: 07 jul 2020.

SOUZA, L. B.; HÜBNER, L. C. A relação entre desempenho em compreensão leitora e fatores socioeconômicos. Fórum Linguístico, ISSNe 1984-8412, v.14, n.2 Florianópolis, 2017. DOI: https://doi.org/10.5007/1984-8412.2017v14n2p2044.

STERN, Y. Cognitive reserve in ageing and Alzheimer's disease. The Lancet Neurology, v. 11, n. 11, p. 1006-1012, 2012. DOI: 10.1016/S1474-4422(12)70191-6

STERNBERG, R. J. Psicologia Cognitiva. 5a .ed. São Paulo: Cengage Learning Edições Ltda., 2010.

TRAXLER, M. J. Introduction to Psycholinguistics: understanding language science. Oxford: Wiley-Blackwell, 2012.

WARREN, P. Introducing psycholinguistics. Cambridge: Cambridge University Press, 2013. 